\title{
The liveability of historical cities: current state and prospects for habitation
}

\author{
S. Treija, U. Bratuškins, S. Barvika \& E. Bondars \\ Faculty of Architecture and Urban Planning, \\ Riga Technical University, Latvia
}

\begin{abstract}
The world's most liveable cities have been ranked on the basis of their residents' living conditions. A functioning residential area is essential for the downtown areas of historical cities as they initially developed as places for people to live. Despite the overall growth of urban economics and city populations, many internationally recognized historical and cultural cities are at the forefront of the fastest shrinking cities in Europe. This highlights a fundamental problem in the current planning and management of historical cities: the physical preservation of old residential buildings has practically been ensured, but this has not guaranteed their further use for habitation. This paper presents the results of a case study of the Historical Centre of Riga (HCR) and aims to identify problems regarding the well-known, but still less explored phenomenon of the "loss of liveability" within the historical centre of the city. The available literature on the problem of urban shrinkage and statistical data was studied in this case study, and a survey on the satisfaction of the residents residing in the Historical Centre of Riga was conducted and the results analysed.

Keywords: liveability, residential function, historical residential buildings, UNESCO heritage, Historical Centre of Riga.
\end{abstract}

\section{Introduction}

Today, many people decide to spend their time and money on travelling around the world to enjoy historical places and different cultures. However, when it comes to choosing a family residence, they prefer to settle in modern residential suburbs and avoid crowded historical locations. This paper will discuss aspects of the liveability of dense historic urban environments in relation to current urban 
problems, urban planning theory and its practical application, as well as the management of urban systems (e.g. from a global to a local level).

Despite the overall growth of global urban economies, over the past two decades a quarter of cities all over the world and one-third of European cities with more than 200,000 inhabitants have experienced irregular habitation (loss of liveability) a notable decline in population (more than 10 percent in a two-year period) $[1,2]$.

A significant number of internationally recognized historical cities (e.g. Rome, Milan, Porto, Riga) are among the fastest shrinking cities in Europe. Their historical vicinities are continuing to lose their residents and are gradually becoming low-density urban territories and "historical" brownfields with deserted buildings, the value of which are decreasing [3, 4].

This highlights a fundamental problem in the current planning and management model of historical cities: the physical ("authentic appearance") preservation of historical residential buildings has been practically ensured and is strictly supervised, but this has not guaranteed the further use of the historical residential areas for living [2].

A well-performing residential stock is essential for the downtown areas of historical cities - as they were initially developed for people to live in [5-7]. Several countries have adjusted their increasing need to maintain the liveability of historical locations in different ways by pursuing distinctive strategies for accommodating people, for example, by adopting inclusionary and affordable housing policies within densely built historical districts (among others, inclusionary ordinances, value recapture instruments, social design and place shaping) or the use of densification and re-urbanization policies (mostly observed in wealthier countries) $[5,8-10]$.

Still, there is no clear answer as to the type of criteria which should be taken into account to prevent and to monitor the depopulation of historical urban locations. Socio-economic statistics (about demographics, employment, school performance, living conditions of permanent residents) has shown that "a liveability gap" exists between the desirable (planned) and the current (real life) urban conditions $[11,12]$.

Within this context, a research to provide a better understanding of the nature and causes of liveability problems in historical urban areas has developed. The authors chose the specific historic residential area in Riga as case study for an indepth research. The main data sources are the results of a residents' questionnaire on the quality of life in the Historical Centre of Riga (HCR) which was conducted in 2014 by the Riga Municipality. In addition, all relevant sources about liveability issues - including statistical data - were scrutinized.

\section{Conceptual framework}

The loss of liveability is mentioned as the most dangerous risk in the preservation of the residential function in historical districts and the most common reason for the formation of residential brownfields (unoccupied, protected historical estates in physically bad condition, usually with a low ratio of building rights) [5]. 
UNESCO's periodic survey about endangered World Heritage in Europe concluded that a weak application of preservation activities was a threat to the successful preservation of the cultural heritage sites [4].

Many theories and models of urban systems have been developed at different times and for various purposes (e.g. smart cities, green cities, liveable cities and cultural cities) centred around the principle of sustainability [11, 13-15]. However, sustainability still remains mostly a global and less practical (only locally implementable) paradigm, particularly in land use management and planning. Moreover, the major challenge for contemporary urban planning and, probably, the main cause for the emergence of the "liveability gap", is the growing complexity and holism of the planning activity due to the large variety of stakeholders, organisations and information involved [11, 16, 17].

There is not a unique definition of liveability (e.g. "the quality of urban living"): it varies from country to country, from city to city and place to place. Generally, liveability is defined as the sum of the factors that add up to a community's quality of life - including the built and natural environments, economic prosperity, social stability and equity, educational opportunity, and cultural, entertainment and recreation possibilities [13, 18, 19]. Liveability, alongside culture, is probably one of the most complex mandatory aspects of sustainable urban development [4].

A new challenge for landlords is to adapt buildings (especially with heritage status) to the contemporary housing standards - requirements of energy efficiency and universal design, as required by EU directives. About 120 million people in the EU live in 55 million residential buildings that were built before 1945 (26 percent of the residential building stock of the EU; 98 percent of all the buildings in the HCR) [9, 19]. Most of the buildings are poorly maintained, have a low market value and very often contribute to the poor aesthetic quality of open spaces which makes the value of adjacent properties decrease. However, a number of privately owned historical residential buildings have been "legally emptied" of "old" tenants (e.g. through the restitution of property rights and privatization in Latvia), refurbished, and transferred from residential to more valuable tenements, well maintained and reoccupied (e.g. rented out or sold to wealthy locals and foreigners). Investments in public infrastructure and space have prompted a steep rise in property prices and local tax levies [20-23]. In turn, many local residents have been forced to leave traditional locations and to settle elsewhere, usually in socially considered less prestigious housing, due to the rapidly growing financial burden on their current residence [6, 24-26]. Residential buildings in historical areas are occupied to a lesser degree than in new residential districts [7]. Consequently, there is a high risk of environmental, social and cultural degradation in the historical areas.

Nowadays, the highly complex social, economic, cultural and management contexts and the problem of urban liveability are better understood through a comprehensive analysis of human activities. First, the economic potential of places - such as the best use of land, employment from local businesses, tax revenues and the property market - must be considered. Second, further consideration must be given to the effects of urban liveability on the social and cultural sphere, such 
as inequity, the complex model of urban social structure, the variety of beliefs and cultures vs. commonly shared values, the loss of traditional values and landmarks, the "living heritage" and the use of greenfield [25, 27]. Finally, urban liveability is defined by the consumption of greenfield such as the use of land as a commodity and the promotion of unlimited urban sprawl [25, 27].

Liveability always refers to the environment from the perspective of the individual. People attach meaning to the environment, and some of the meanings are based on their needs, which may form the basis to measure liveability [28]. In the literature concerning "liveability", there are different views about the dimensions that should be included in this concept. To a large extent, these views stem from different disciplines. Still, mixed-use neighbourhoods with affordable homes are usually considered an example of liveable habitation. In liveability studies in European cities, the perception of liveability is usually measured along four dimensions [28]:

- The quality of the dwelling/ building;

- The quality of the physical environment, including the level of services and facilities;

- The quality of the social environment;

- The safety of the neighbourhood.

Liveability problems in residential areas are a complex phenomenon, which differ according to the locality $[28,29]$.

\section{Methodology}

The aim of the research was to get a better understanding of liveability problems in the historic housing areas of Riga. The research questions are the following:

- What liveability problems exist in historic housing areas in Riga?

- Which factors influence these problems?

The theoretical framework of this paper is based on an analysis of international and local research and documents in connection with urban planning, economic and social theories and practices, theories and practices of the planning of historical heritage and theoretical and legal principles of spatial planning in connection with cultural heritage protection. The following research methods were applied: the empirical approach (for an analysis of the theoretical sources of urban planning and its connection to cultural heritage preservation); quantitative research (for studying and processing of socio-economic statistics, surveys of satisfaction of residents and spatial planning information). An analysis of local spatial planning regulations and relevant statistics has also been carried out. 


\section{Redevelopment challenges in the Historical Centre of Riga (HCR)}

A unique urban design site in Latvia and North-Eastern Europe - the HCR (Figure 1) which is included in the UNESCO list of heritage sites, and its historical residential buildings, were selected as the object of this study.

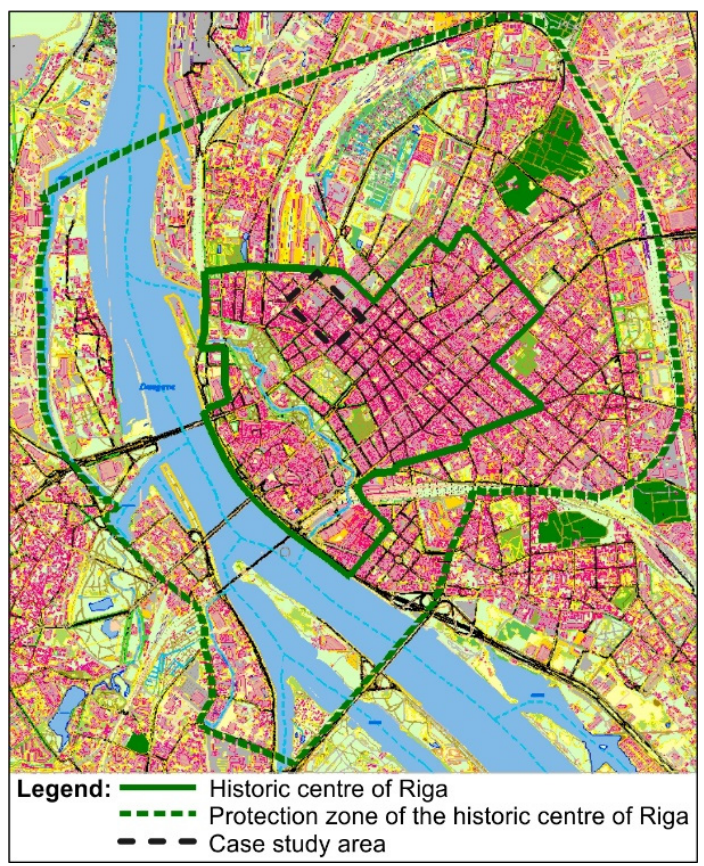

Figure 1: Location of the HCR and case study area in Riga [30].

The core of the city, the historical centre stands out for its outstanding urban space qualities. Although the HCR occupies only 1.43 percent of the area of the city, it is the business, employment, tourism and cultural centre of Riga. Since 1990, negative demographic trends have continued (as shown in Table 1) and, Riga has now lost almost 28 percent of its population with particularly sharp depopulation in the central part of the HCR - its downtown.

Table 1: Number of population in the downtown and in the City of Riga

\begin{tabular}{|l|c|c|c|c|}
\hline Area & 1989 & 2011 & Trend & $\%$ \\
\hline Downtown of Riga & 90 & 30728 & -52145 & -68 \\
\hline City of Riga & 910 & 658640 & -25181 & -28 \\
\hline
\end{tabular}


While a significant increase in emigration and negative natural growth are global problems for cities and countries around Eastern Europe, the privatisation and denationalisation of real estate, the economic crisis, a change of land use and the gentrification trend (resettling historical residents to less-prestigious districts) are rather local trends in HCR. As opposed to what is taking place in the centre of the city of Riga, the population has been increasing in the Riga agglomeration since 2004. The trend for the concentration of the population in the central part of the city has been taken over by the formation of an agglomeration or urban sprawl and a growth in population density in the nearby areas of the city. The HCR provides more than 110,000 jobs ( 40 percent of all employees and 20 percent of all the population of Riga) [7,31]. Deep transformations in the socio-economic context bring up essential questions concerning the future of historical cities. The preservation of heritage and the need for economic development, while respecting the liveability criteria, represents a complex system of tasks for the development of the HCR. More than 200 cultural monuments of state and local significance are concentrated within the limits of the compact territory of the HCR and its Protection Zone (PZ). These buildings have strict regulations that limit their exterior and interior renovation and prevent their demolition. The initiation of new development on unbuilt or on partly built land plots undergoes strict institutional screening and can be subject to archaeological scrutiny and public reviews in connection with the Riga Master Plan, the Master Plan of the HCR and its PZ, and Building Law. Much of the existing housing stock in HCR is relatively outdated: more than 80 percent of the buildings were built prior to 1940 and an average of 60 percent have depreciated (Figure 2).

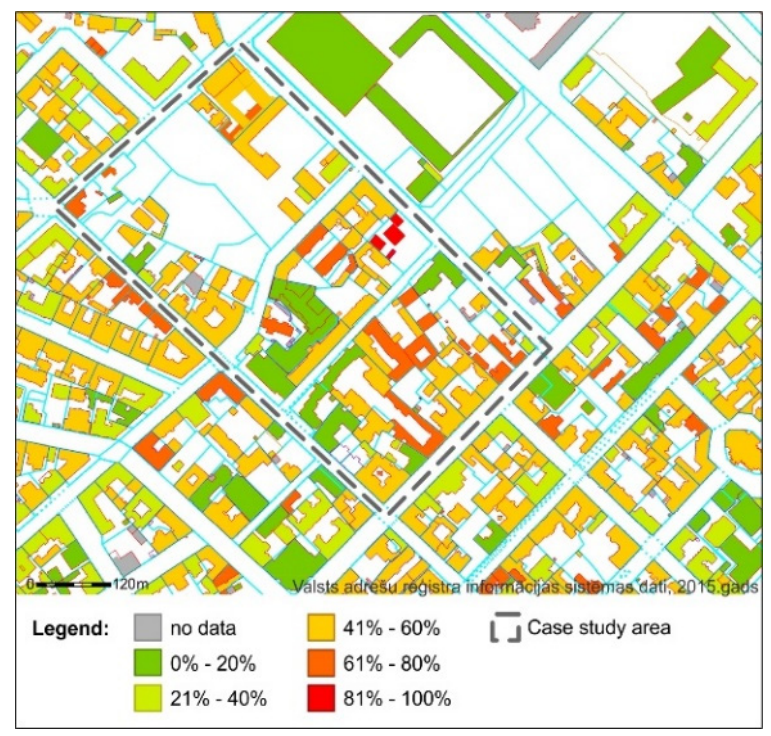

Figure 2: Building depreciation in a selected area of HCR. (Source: www.kadastrs.lv.) 
In 2016, the city council estimated that in Riga, 40 buildings were not occupied and have been recognized as "degraded objects of public space"; 500 buildings (in both, private and municipal ownership) had poor visual quality and were not fully occupied. Meanwhile, municipalities continue to struggle with the shortage of social housing. The residential function, which has historically been the dominant use in the HCR, has in recent decades been significantly reduced. This is evidenced by data on unoccupied housing and the replacement of housing with business services and retail.

\subsection{Planning strategy in the Historical Centre of Riga}

The "Riga Historical Centre Preservation and Development Plan" (2013) furnishes a consistent policy for housing preservation and development in the territory of the HCR [30]. Land use planning for the HCR and its PZ is well supported by a sound legal regulation. Zoning allows mixed land use in the entire HCR and its PZ to promote the diversity of prospective land use and in the remodelling of current structures, sets provisions (proportions in percent) for public space, parking lots and the street area. In mixed territories, land and buildings (mainly multi-storey) can be used for apartments, businesses, services, residential buildings (low-storey buildings in several territories), allowing business and services space on the lower storeys. The proportions of the various types of users differ, depending on the locations and could fluctuate for residential function. Smaller buildings in the central territories typically have dwellings of 40 percent or less whereas the larger buildings in the central territories have dwelling proportions of 40 percent or more, which is also an indication of high living standard. This means that the housing function for a particular area of the property is planned as the main or predominant use for the building, and other purposes are subordinated to it. Functions other than housing services are allowed to use only the lower floors of buildings, mainly those which look onto the street, are allowed to use the lower floors for services other than housing. One of the tasks of HCR housing policy is also to promote social diversity in the population and provide a sufficient quantity of housing which meets the needs of certain population groups, such as families with minor children, older people and people with special needs and special requirements.

Within this legal framework, 14 residential buildings with 632 apartments were built from 2006 to 2015 in the HCR neighbourhoods. All the new projects have been the initiative of a private investor. The price level of the apartments has been significantly higher than the city average and unaffordable to those on middle and low incomes.

\subsection{Urban densification in the Historical Centre of Riga}

Some typical urban blocks in the HCR help to illustrate current processes (Figure 3 ). A group of three urban blocks, situated at the northern edge of the HCR, reveal a wide spectrum of activities characteristic of urban gentrification: the renovation of heritage buildings, the construction of new housing, adjacent areas which 
remain abandoned, a steep increase in housing prices and changes in the population structure.

Most of the buildings in this area were built at the late 19th and early 20th century, when active development took place in tandem with the rapid economic "boom" in the city. Fifteen buildings are included on the list of protected buildings (Figure 4), as recognized monuments of national or local importance. Nineteen other buildings have been assessed as important cultural and historical heritage by the Master Plan of the HCR.

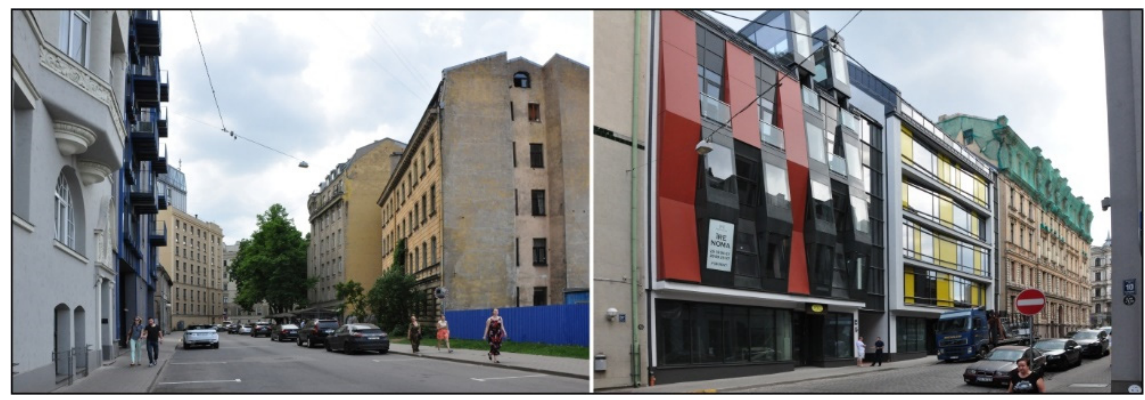

Figure 3: Selected area of HCR. Left: typical street view, right: new construction next to abandoned buildings. Photography from S. Treija's personal archive.

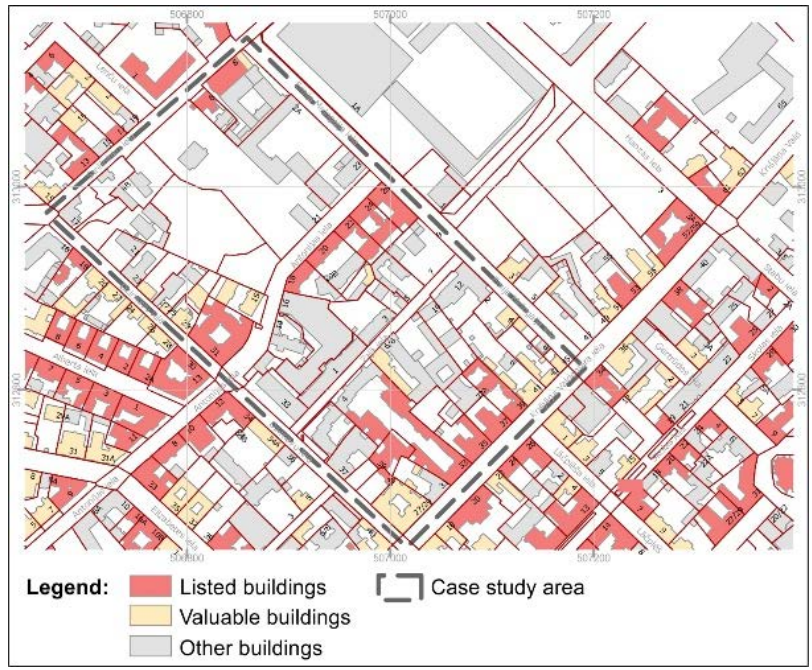

Figure 4: Listed buildings in a selected area of the HCR. (Source: HCR GIS.)

These buildings have spacious apartments which do not meet the demands of the average residents. During the Soviet period, these apartments were used to house several families due to the rapid urban growth and the ensuing housing 
shortage. After the land reforms that took place in the 1990s, the majority of these buildings were emptied of "old" residents, renovated and reconverted back to upper class housing or redeveloped for office space.

\subsection{The results of the survey}

A survey of residents of 11 neighbourhoods in Riga was carried out in 2014 by Riga City Development Department to gauge public opinion on the living quality in the HCR and its PZ. A total of 374 respondents participated in the survey conducted in the case study area. The results confirmed the hypothesis about population change in the HCR - 47 percent of the population have lived in their current housing for less than 10 years, of whom 35 percent have done so for less than 5 years. 22 percent of the respondents had considered moving outside the HCR. The main reasons for wanting to move are: to enjoy a cheaper life (20 percent), as well as a desire for silence (13 percent) and a better residence (13 percent).

\subsubsection{Quality of the social environment}

The majority of the respondees, about 70 percent, tend to agree with the statement that they know their neighbours and greet them. Like most of the population (54 percent), they believe that people in their neighbourhood are willing to help their neighbours. Still, 57 percent of residents do not experience a sense of belonging to the neighbourhood.

\subsubsection{Quality of the physical environment}

In this neighbourhood, most people come to enjoy shopping ( 87 percent), to visit the family doctor ( 51 percent) and to attend cultural events ( 48 percent). According to the survey, the following types of amenities generated most satisfaction among residents/people: restaurants (92 percent), cultural institutions ( 89 percent), and shopping centres ( 89 percent). Almost half of the population (49 percent) indicate that they would like more cycle paths, while 47 percent want more sports and playgrounds.

\subsubsection{Quality of dwellings/buildings}

The residents believe that vast improvements are needed in the quality of courtyard utilities (82 percent), the appearance of residences ( 84 percent), residential services ( 83 percent), and the energy efficiency of residential buildings ( 84 percent). 85 percent of the population are very satisfied or rather satisfied with their housing. The majority of the residents (38 percent) live in dwellings with an area at least $61 \mathrm{~m}^{2}$, while about 6 percent live in an area of less than $30 \mathrm{~m}^{2}$.

\subsubsection{Safety of the environment}

Most residents expressed satisfaction with the street lighting at the front of the house (93 percent) and the safety of homes in the neighbourhood during the day (91 percent) and night (73 percent).

The overall analysis of the results of the survey shows that population turnover in the neighbourhood is high and that there is weak sense of community. Since 
housing with different quality are available, there is also diverse social composition of the population. Residents are mostly satisfied with services provided and unsatisfied with outdated dwellings.

\section{Conclusions}

The case study revealed that there is wide diversity with regard to the nature and possible causes of liveability problems, that the liveability issue is a complex phenomenon and that the problems are specific for each housing area. In the HCR, many unused or less-occupied historical buildings are under risk of not being preserved or used. Although the mechanisms for value capture of architectural heritage in the HCR and its PZ do exist, they are not fully implemented due to insufficient funding (e.g. a lack of state budget funding for the restoration of historical buildings and the slow implementation of housing policy). Funding the preservation of cultural heritage sites is subordinate to other national priorities such as maintaining the fiscal stability of the country. In addition, housing policy, creation of tax reliefs for owners of cultural monuments and the promotion of local residential markets, all seem to be of secondary priority. The development tendencies - the renovation process of historic buildings with the aim to convert them to a higher standard of dwellings, as well as the construction of new buildings for the exclusive housing market - are manifestations of a process of gentrification.

\section{References}

[1] Frantzeskaki, N., Urban Resilience: A concept for co-creating cities of the future, 2016. http://urbact.eu/sites/default/files/resilient_europe_baseline_ study.pdf.

[2] UN HABITAT, Issue paper on urban culture and heritage. Habitat III Issue Papers, 2015.

[3] UN HABITAT, Housing and slum upgrading, 2016. http://unhabitat.org/ urban-themes/housing-slum-upgrading/.

[4] UNESCO World Heritage Centre, World Heritage Cities Programme, 2005. http://whc.unesco.org/en/cities/.

[5] Colini, L., EU urban agenda: The challenge of "affordable housing" in Europe, 2016. https://urbact.eu/eu-urban-agenda-challenge-affordablehousing-europe.

[6] Eurostat, Housing cost overburden rate by tenure status, EU-SILC survey, 2015.

http://ec.europa.eu/eurostat/tgm/table.do?tab=table\&init=1\&language=en \&pcode=tessi164\&plugin $=1$.

[7] Final results of the Population and Housing Census 2011 - Riga, Population and Housing Census, 2011.

[8] Beyer, S., Inclusionary zoning is rent control 2.0. Forbes, 2015. www.forbes.com/sites/scottbeyer/2015/05/27/inclusionary-zoning-is-rentcontrol-2-0/. 
[9] Directorate General for Research, Housing policy in the EU member states, working document, 1996. www.europarl.europa.eu/workingpapers/soci/ w14/text1 en.htm.

[10] Advisory Council on Historic Preservation, Affordable Housing and Historic Preservation: Council Policy Statement Adopted June 26, 1995, The Council: Washington DC, 1998.

[11] Campbell, S., Green cities, growing cities, just cities? Urban planning and the contradictions of sustainable development. Journal of the American Planning Association, 62(3), pp. 296-312, 1996.

[12] Institute for Local Self Government, Annotated sample inclusionary housing ordinance. California Inclusionary Housing Reader, Institute for Local Self Government: Sacramento, pp. 119-149, 2003.

[13] Mah, J., CPRN: Can Inclusionary Zoning Help Address the Shortage of Affordable Housing in Toronto? Canadian Policy Research Networks (CPRN): Toronto, 2009.

[14] Smith, S., Why I don't like inclusionary zoning. Market Urbanism, 2010. http://marketurbanism.com/2010/12/28/why-i-dont-like-inclusionaryzoning/.

[15] UNESCO, Creative cities, UNESCO creative cities network, 2004. http://en.unesco.org/ creative-cities/.

[16] Rypkema, D.D., Heritage conservation and the local economy. Global Urban Development Magazine, 4(1), 2008. www.globalurban.org/GUD Mag08Vol4Iss1/Rypkema.htm.

[17] UPAT and International Society, Livable cities in a rapidly urbanizing world. International Society of City and Regional Planners (ISOCARP): Singapore, 2010.

[18] Newman, P.W.G., Sustainability and cities: Extending the metabolism model. Landscape and Urban Planning, 44(4), pp. 219-226, 1999.

[19] Russell, L., Historic preservation: Smarter growth and better affordable housing, 2013. http://smartcommunities.typepad.com/suzanne/2013/05/ historic-preservation-smarter-growth-and-better-affordable-housing.html.

[20] Warren Myers, G., The value of sustainability in real estate: A review from a valuation perspective. Journal of Property Investment and Finance, 30(2), pp. 115-144, 2012.

[21] Kalantari, M. \& Rajabifard, A., Spatially referenced legal property objects. Land Use Policy, 25(2), pp. 173-181, 2008.

[22] Rypkema, D.D., Cheong, C. \& Mason, R., Measuring economic impacts of historic preservation: A report to the Advisory Council on Historic Preservation. University of Pennsylvania: Washington DC, 2011.

[23] Wassmer, R.W., Further Empirical Evidence on Property Taxation and the Occurrence of Urban Sprawl, Lincoln Institute of Land Policy, 2016.

[24] Delvac, W.F. et al., Affordable Housing through Historic Preservation: A Case Study Guide to Combining the Tax Credits, US Department of the Interior, National Park Service, Cultural Resources, Preservation Assistance, National Trust for Historic Preservation: Washington DC, 1994. 
[25] Guštin, M. \& Nypan, T., Cultural heritage and legal aspects in Europe. Institute for Mediterranean Heritage and Institute for Corporation and Public Law, Science and Research Centre Koper, University of Primorska: Koper, Slovenia, 2010.

[26] Richter, C.A. \& Sullivan, E.J., Three most influential planning cases of 2015: Affordable housing, historic preservation and limits to local government decision-making. Oregon Chapter of the American Planning Association, 2015. www.oregonapa.org/three-most-influential-planningcases-of-2015-affordable-housing-historic-preservation-and-limits-tolocal-government-decision-making/.

[27] Kauko, T., Sustainable development of the built environment: The role of the residential/housing sector. Sustainable Development - Education, Business and Management - Architecture and Building Construction Agriculture and Food Security, INTECH Open Access Publisher: London, pp. 161-174, 2012.

[28] Heylen, K., Liveability in social housing: Three case-studies in Flanders. ENhR International Conference, Workshop 18 Residential Environments and People, Ljubljana, Slovenia, 2006. https://lirias.kuleuven.be/bitstream/ 123456789/288700/1/W18_Heylen.doc.

[29] European Parliament, Report on social housing in the European Union: A70155/2013, 2013.

[30] Saeima (The Parliament of the Republic of Latvia), Law on Preservation and Protection of the Historic Centre of Riga (In Latvian: Likums Par Rìgas vēsturiskā centra saglabāšanu un aizsardzību), working version, 2016. www.saeima.lv/bi8/lasa?dd=LP00180.

[31] State Statistical Office of the Latvian SSR, Results of the all-union population and housing census 1989, Latvian SSR, 1990. www.csb.gov.lv/ en/dati/e-publikacijas/results-all-union-population-and-housing-census1989-latvian-ssr-demographic-ind. 